\title{
Análíse crítica da gestão do saneamento do estado do Mato Grosso, Brasil
}

DOI: $10.20396 /$ labore.v13i0.8652832

Submetido 06 mai. 2019.

Aceito 30 out. 2019.

Publicado 09 nov. 2019
Larissa Rodrigues Turini

$<$ https://orcid.org/0000-0002-2841-7807>

Universidade Federal do Mato Grosso/ Cuiabá [MT] Brasil

Eliana Beatriz Nunes Rondon Lima

$<$ https://orcid.org/0000-0002-0378-9778>

Universidade Federal do Mato Grosso/ Cuiabá [MT] Brasil

Gabriel Figueiredo de Moraes

<https://orcid.org/0000-0002-5137-1421>

Universidade Federal do Mato Grosso/ Cuiabá [MT] Brasil

\section{RESUMO}

Este estudo mostra uma ampla análise do impacto causado por modelos de gestão do saneamento no Estado de Mato Grosso a partir da mudança do modelo centralizado para descentralizado onde, cada município passou a gerir os seus próprios sistemas de abastecimento de água. Os impactos da mudança foram analisados considerando as dimensões: gerencial, técnico-operacional, social, ambiental a partir da definição de indicadores para avaliar a evolução do setor após 20 anos de vigência desse do novo modelo. A análise teve como base os dados do Projeto denominado - Plano de Saneamento de 106 municípios do Estado de Mato Grosso (PMSB-MT) que envolveu a participação de três entes federados do País (União, Estado e Município) para elaborar dos planos municipais de saneamento de 106 municípios com população inferior ou igual a 50.000 habitantes, considerando as perspectivas de governança e sustentabilidade previstas na Lei $\mathrm{n}^{\mathrm{o}}$ 11.445/2007. A metodologia compreendeu uma abordagem quantitativa, que resultaram em um diagnóstico técnico das infraestruturas existentes e das condições operacionais e da capacidade gerencial dos municípios na prestação dos serviços. Os resultados são discutidos em relação aos indicadores para avaliar aos índices atendimento na cobertura dos serviços, tipo de captação, índice de hidrometração, perdas e inadimplência. O modelo descentralizado não obteve êxito dos municípios, uma vez que estes não foram capacitados e treinados para a prestação dos serviços gerando inúmeros, problemas independentes ao tipo de prestação de serviço.

\section{PALAVRAS-CHAVE}

Sustentabilidade. Governança. Prestação. Diagnóstico. Abastecimento de água. Indicadores.

\section{Critical analysis of the sanitation management of the state of Mato Grosso, Brazil}

\section{ABSTRACT}

This study shows a broad analysis of the impact caused by sanitation management models in the state of Mato Grosso from the change from centralized to decentralized where each municipality started to manage its own water supply systems. The impacts of the change were analyzed considering the following dimensions: managerial, technicaloperational, social, environmental from the definition of indicators to evaluate the evolution of the sector after 20 years of validity of this new model. The analysis was based on data from the Project entitled — Sanitation Plan of 106 municipalities of the State of Mato Grosso (PMSB-MT) involving the participation of three federated entities of the Country (Union, State and Municipality) to elaborate the municipal plans of sanitation of 106 municipalities with a population of less than or equal to 50,000 inhabitants, considering the perspectives of governance and sustainability provided by Law $11455 / 2007$. The methodology comprised a quantitative approach, which resulted in a technical diagnosis of the existing infrastructures and the operational conditions and the managerial capacity of the municipalities in the provision of services. The results are discussed in relation to the indicators to evaluate the service coverage indexes, type of funding, hydrometric index, losses and delinquency. The decentralized model was not successful in the municipalities, since they were not trained and trained to provide the services generating innumerable, independent problems to the type of service rendering.

\section{KEYWORD}

Sustainability. Governance. Installment. Diagnosis. Water supply. Indicators. 


\section{Introducãa}

A Companhia de Saneamento do Estado de Mato Grosso - SANEMAT, criada no final da década de 1960, integrando a estrutura institucional desenhada pelo Plano Nacional de Saneamento Básico - PLANASA, tinha nas companhias estaduais - CEB`s, a prerrogativa para gerenciar os serviços de saneamento, água e esgoto dos municípios por meio de uma outorga dada ao Estado. Durante três décadas, a SANEMAT foi responsável pelo gerenciamento dos sistemas de abastecimento e esgotamento dos municípios. Porém esse modelo centralizador entrou em declínio, decorrente dos passivos trabalhistas, de impostos tributários e incapacidade gerencial para atender as demandas dos municípios (Teixeira \& Lima, 1999).

No final da década de 90, na visão do Estado, a municipalização dos serviços de saneamento teria como principal objetivo melhorar a qualidade dos serviços de água e esgoto nos municípios, bem como reduzir os custos destes serviços para a população. O Estado, então, devolveu aos Municípios a responsabilidade pela prestação dos serviços no que se refere à distribuição e garantia da qualidade de água e tratamento de esgoto, em virtude da extinção dos vínculos existentes entre os Municípios e a SANEMAT.

De acordo com a lei a prestação dos serviços pode se dar de forma direta, indireta e por delegação. A delegação da prestação dos serviços públicos de saneamento básico é entendida como a concessão dos serviços precedida de licitação pública (artigo 175, caput, da Constituição Federal, e Lei no 8.987/1995).

Existe, também, a cooperação federativa, exercida obrigatoriamente por meio de contrato de programa (artigo 13 da Lei no 11.107/2005). Neste caso, os municípios em convênio de cooperação com os Estados poderão contratar as Companhias de Saneamento Estaduais, com dispensa de licitação, mediante contrato de programa. Também poderão, de forma voluntária, se agrupar, com a participação do Estado, formando consórcios públicos para cooperarem entre si.

Esta análise proposta se baseia nos princípios norteadores pela lei 11.445/2007 e pelo decreto regulamentador $\mathrm{n}^{\circ} 7.217$, de 21 de junho de 2010, que impôs ao setor um novo ordenamento institucional com a separação das atividades de planejamento, prestação de serviço, regulação e controle social e a partir dessa legislação buscou-se avaliar o modelo atual vigente no estado de Mato Grosso e a evolução desses indicadores de forma a se verificar a eficácia do modelo adotado pelo Estado. A hipótese norteadora deste estudo é que os indicadores dos serviços de água apontam para uma situação de estagnação e retrocesso na prestação dos serviços em decorrência da ausência dos planos de saneamento que estabelecessem as diretrizes e metas a serem adotadas ao longo de um horizonte temporal com objetivo de atender aos princípios da lei: universalização dos serviços, integralidade, sustentabilidade, intersetorialidade das políticas, da necessidade de criar um ente regulador que atuasse na fiscalização e regulação dos serviços prestados e de um efetivo controle social.

O PMSB - MT foi elaborado a partir de uma parceria entre a FUNASA, Governo do Estado e a Universidade Federal do Mato Grosso para a execução de106 planos para municípios com população inferir a 50.000 hab. e posteriormente a inclusão de mais dois municípios. A concepção do projeto considerou as delimitações dos consórcios intermunicipais existentes no Estado e compreendeu o atendimento de 14 do total de 15 consórcios. A população atingida foi de 1.335 .656 habitantes o que representa $77 \%$ da população do Estado. Envolveu levantamento de campo em 106 áreas urbanas.

\section{Metodologia}

A metodologia compara os indicadores de água após 20 anos de municipalização dos serviços de água do estado. A base de dados utilizados neste estudo refere-se aos trabalhos de Teixeira (1999) do estudo realizado pela Secretaria Nacional de Saneamento por meio do Programa de Modernização do Setor de Saneamento - PMSS e o diagnóstico atual realizado pelo projeto Plano Municipal de Saneamento de106 Municípios do Estado de Mato Grosso.

\subsection{FONTES}

No Quadro 1 encontram-se listados os documentos que serviram de base da pesquisa documental com referência aos anos em que os dados foram obtidos das fontes. 
Quadro 1. Fontes e períodos relativos a prestação de serviços.

\begin{tabular}{|c|c|c|c|c|c|}
\hline Documentos & $\begin{array}{c}\text { Ano de } \\
\text { Referência }\end{array}$ & $\begin{array}{c}\text { Tipo de } \\
\text { Prestacâo } \\
\text { predominante }\end{array}$ & Fonte dos dados & $\begin{array}{l}\text { Número de } \\
\text { municipios } \\
\text { analisados }\end{array}$ & $\begin{array}{l}\text { Percentual de } \\
\text { atendimento } \\
\qquad(\%)\end{array}$ \\
\hline $\begin{array}{l}\text { Monografia de especializacao em } \\
\text { Saneamento Ambiental e } \\
\text { Recursos Hidricos }\end{array}$ & 1998 & $\begin{array}{l}\text { Companhia } \\
\text { Estadual de } \\
\text { Saneamento } \\
\text { responsavel }\end{array}$ & SANEMAT & 92 & 91 \\
\hline $\begin{array}{l}\text { Estudos do PMSS } \\
\text { Descentralização da prestação dos } \\
\text { serviços de água e esgotamento } \\
\text { sanitario no caso do Estado de } \\
\text { Mato grosso }\end{array}$ & 2008 & $\begin{array}{c}\text { Modelo } \\
\text { descentralizado }\end{array}$ & AGER & 141 & 100 \\
\hline $\begin{array}{l}\text { Projeto do Plano de Saneamento } \\
\text { de } 106 \text { municípios do estado de } \\
\text { Mato Grosso }\end{array}$ & 2017 & $\begin{array}{c}\text { Modelo } \\
\text { descentralizado }\end{array}$ & $\begin{array}{c}\text { UFMT/FUNASA/ } \\
\text { SECID }\end{array}$ & 106 & 77 \\
\hline
\end{tabular}

Fonte: Autores.

\subsection{ETAPAS METODOLÓGICAS DO PROJETO}

A metodologia adotada para a realização do Plano Municipal de Saneamento Básico - PMSB foi elaborado um levantamento preliminar dos dados secundários existentes nos diversos órgãos públicos e prestadores de serviços públicos e privados. Para melhor entendimento de todo as etapas referentes à elaboração do Plano Municipal de Saneamento Básico - PMSB, por partes dos comitês executivos e de coordenação, foi realizada uma capacitação nas sedes dos consórcios para orientação e entrega dos formulários relacionados a cada componente do saneamento básico. Estes comitês foram formados com representantes do poder público municipal, que juntamente com a equipe executora da UFMT, integram o grupo de trabalho e atende as exigências do Termo de Referência da FUNASA quanto ao Produto B-Plano de Mobilização Social. Posteriormente, foi realizada visita in loco, tendo como ponto de partida o diálogo com a Prefeitura Municipal e, em particular, com as secretarias municipais envolvidas na prestação dos serviços nos quatro eixos elencados, intermediado pela ação do comitê executivo designado pelo gestor.

A metodologia adotada para realização deste diagnóstico constituiu no levantamento de dados primários a partir do levantamento de campo na área urbana do município, e ainda de um extenso levantamento e compilação dos dados secundários existentes nos diferentes órgãos públicos, tais como: SNIS, IBGE, FUNASA, Anuário Estatístico, etc. Todos os dados obtidos estão disponíveis em um banco de dados que integra o sistema de gerenciamento do projeto. Nesse sistema encontram-se armazenados também, os dados primários, secundários, plantas, mapas e imagens, referentes ao município com a indicação da Unidade de Planejamento e Gestão - UPG, da bacia hidrográfica em que o município está inserido.

\subsection{INDICADORES}

O Quadro 2 apresenta os indicadores utilizados para análise do sistema de saneamento de água de cada município.

Quadro 2. Indicadores utilizados para análise do sistema de saneamento.

\begin{tabular}{|l|l|}
\hline \multicolumn{2}{|c|}{ Indicador } \\
\hline $\begin{array}{l}\text { Índice de atendimento urbano com } \\
\text { Abastecimento de Água }\end{array}$ & $\begin{array}{l}\text { Avaliar o grau de universalização da população urbana atendida com o } \\
\text { serviço de Abastecimento de Água, face às metas estabelecidas no PMSB }\end{array}$ \\
\hline Índice de intermitência na distribuição de água & $\begin{array}{l}\text { Avaliar a melhoria da qualidade do serviço de distribuição da água a partir } \\
\text { do início da execução do PMSB }\end{array}$ \\
\hline Índice de cobertura de Hidrometração & $\begin{array}{l}\text { Avaliar a cobertura de hidrometração das ligações de água ativas, face às } \\
\text { metas estabelecidas no PMSB } \\
\text { Índice de perdas na produção de água }\end{array}$ \\
\hline
\end{tabular}

Fonte: PMSB-MT, 2016. 


\section{Resultados e discussões}

Os resultados apresentados demonstraram que ao longo desses 20 anos o modelo descentralizado vigente se caracterizou como um processo desarticulado e com um distanciamento do Estado que até os dias atuais não adequou a Política Estadual de Saneamento em conformidade com a lei 11.445/2007. Dessa forma verifica-se a necessidade de um ordenamento institucional para lidar com as atividades de planejamento, regulação, prestação de serviços e controle social para fazer frente à melhoria dos indicadores de abastecimento e na qualidade dos serviços prestados.

\subsection{Planejamento}

As exigências para que o município no Estado de Mato Grosso elabora sem seus planos de saneamento revelou dificuldades de ordem técnica, pessoal e financeira, e só foram realizadas mediante o suporte da Fundação Nacional de Saúde - FUNASA - que buscou recursos que pudessem viabiliza-los. Essa situação foi observada por Pereira e Heller (2015) em outras regiões do País. Galvão Junior (2013) comentou a necessidade de prorrogação de prazo devido ao baixo percentual de municípios brasileiros com a existência de Planos e mesmo nos dias atuais verifica-se estados em que persiste essa situação. Com a execução do Projeto do PMSB - MT o estado de Mato Grosso conseguira atingir 100 \% dos Planos de Saneamento. A participação da Universidade foi uma alternativa encontrada pelo governo federal e estadual para solucionar os problemas encontrados de planos que foram elaborados pelos próprios concessionários privados ou por outros que não atendiam as exigências do Termo de referência que estabelecia o envolvimento e participação da sociedade em todo o processo, dentre outras exigências.

Um exemplo emblemático ocorreu na capital do Estado, Cuiabá, em que a construção do um Plano, constituiu no cumprimento de uma mera formalidade, para se efetivar o processo de concessão que encontrava-se em curso e trouxe consequências para a qualidade da prestação dos serviços por não traduzirem um diagnóstico real do sistema encontrado, como fora reclamado pelo próprio concessionário. Lima e Lima (2014) identificaram a necessidade do município de Cuiabá rever com urgência o plano de Saneamento uma vez que pontos importantes foram desconsiderados na sua elaboração e que tem refletido de forma direta na atuação da concessionária. Os autores recomendam ainda que o município, enquanto poder concedente, tem que desempenhar o seu papel e cobrar o pleno cumprimento do contrato.

\subsection{MODELOS DE PRESTAÇÃo DOS SERVIÇOS DE ÁGUA}

O modelo centralizado, vigente durante quase três décadas no Estado, teve a SANEMAT, como concessionária responsável pela prestação dos serviços de água e esgoto em $91 \%$ dos municípios. Com a municipalização no final da década de 90 ocorreu à mudança para um modelo descentralizado, conforme identificado pelo PMSS(2008) em que 56\% (cinquenta e seis por cento) da prestação era realizada diretamente pelo município por meio de departamentos; $18 \%$ (dezoito por cento) dos municípios tinham a prestação indireta, exercida por meio de autarquias municipais; $22 \%$ da prestação por empresa privada, por meio de concessão dos serviços, e $2 \%$ da prestação por empresa privada, por meio de permissão dos serviços. Ainda se cons-
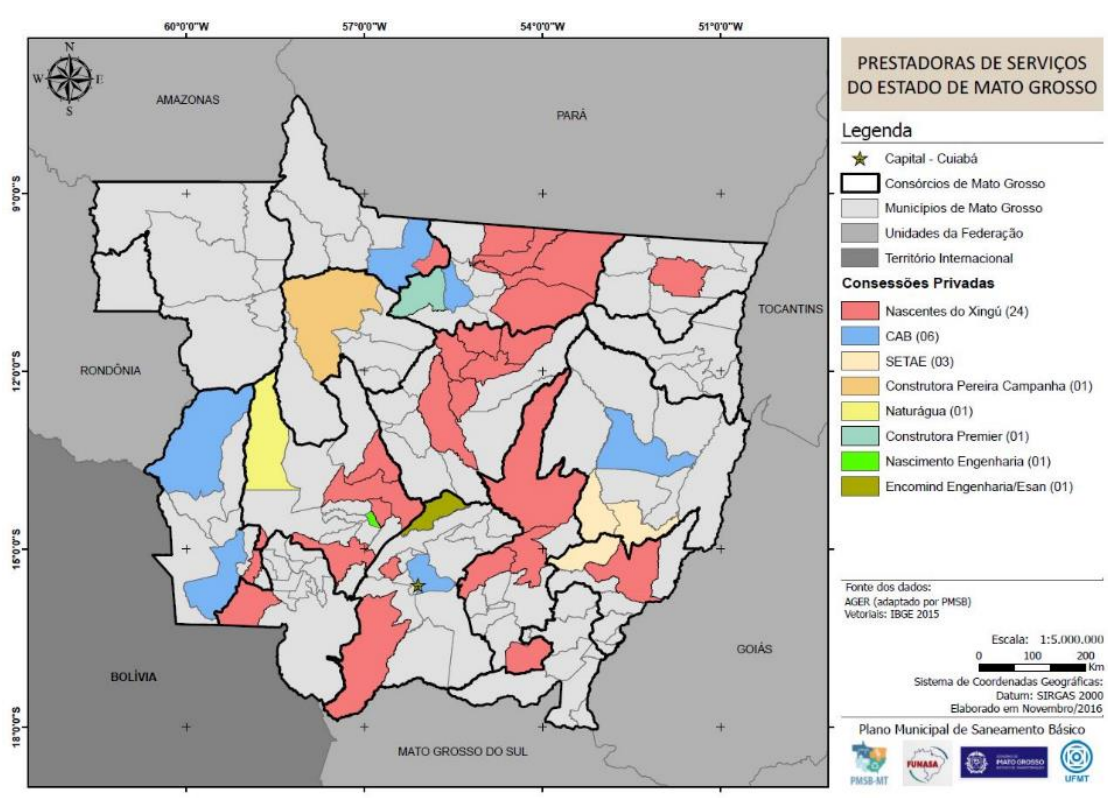
tatou que $2 \%$ (dois por cento) dos municípios do Estado de Mato Grosso não tinham prestador ativo de serviço de saneamento básico. Atualmente a Agência de Regulação do Estado de Mato Grosso - AGER identificou que 103 municípios apresentam prestação pelo titular por departamentos, setores e autarquias e 38 municípios têm prestação por meio de 8 concessionárias privadas, conforme demonstrado na Figura 1. 
A participação da iniciativa privada ocorreu nos municípios com maior potencial econômico, em geral, na região do agronegócio e em municípios com maior renda per capita. Esses números demonstram o avanço da prestação privada no estado, com $27 \%$ dos municípios, representando um dos estados com o maior número de municípios concessionados e com grande potencialidade de ampliação desses serviços ,de acordo com a Associação Brasileiras das Concessionarias - ABCON. Este fato decorre da ausência do estado na gestão dos serviços e configura uma situação muito peculiar, conforme apontado pela Agencia Nacional de Água - ANA (2011) como sendo Mato Grosso a única Unidade da Federação que não conta com uma companhia estadual responsável pelos serviços de água e esgoto. Os resultados desse modelo descentralizado/municipalização levaram, ao longo desses anos, a uma situação de vazio institucional em que o Estado se colocou totalmente ausente do seu papel e responsabilidade compartilhada junto aos municípios e se eximiu de tratar dessas questões.

Teixeira e Lima (2000) apontaram, logo no início dessas mudanças, que o processo de municipalização desencadeado em Mato Grosso causava preocupação quanto aos novos rumos de gestão desses sistemas. As autoras ponderavam que o Estado, ao repassar o papel de operador e não assumir concretamente o de regulador deixa uma lacuna, já que os operadores (municípios/iniciativa privada) não contavam com diretrizes, indicadores e padrões a serem cumpridos pelos seus sistemas de abastecimento e esgotamento sanitário.

Outro aspecto a ser salientado consiste em uma consulta de manifestação de Interesse Privada, em que a empresa AEGEA solicitou a autorização ao governo de Estado a fim de propor alternativas para universalização desses serviços a 96 municípios com população inferir a 35.000 habitantes por meio de uma Prestação Regionalizada. Caso essa iniciativa ocorra há tendência de prevalecer a atuação de uma única empresa, impondo uma configuração de monopólio privado.

\subsection{REGULAÇÃO}

A evolução da regulação no país tem se comportado de forma lenta conforme demostrado por Galvão Junior (2014). Em que apenas 49\% apresentavam seus serviços regulados em função da complexidade de se instituir e, principalmente, de operacionalizar uma agência reguladora. $\mathrm{O}$ autor, ainda acrescenta que os desafios dos municípios, não são pequenos, a começar pela própria definição da entidade reguladora, considerando o contexto da predominância da prestação regionalizada dos serviços de abastecimento de água.

A situação da regulação no Estado, retrata que apenas quatro municípios estão sendo regulados, sendo duas autarquias constituídas, dois municípios conveniados com a Agência Reguladora Estadual e 137 não tem um ente regulador definido, conforme demonstrado na Figura 2.

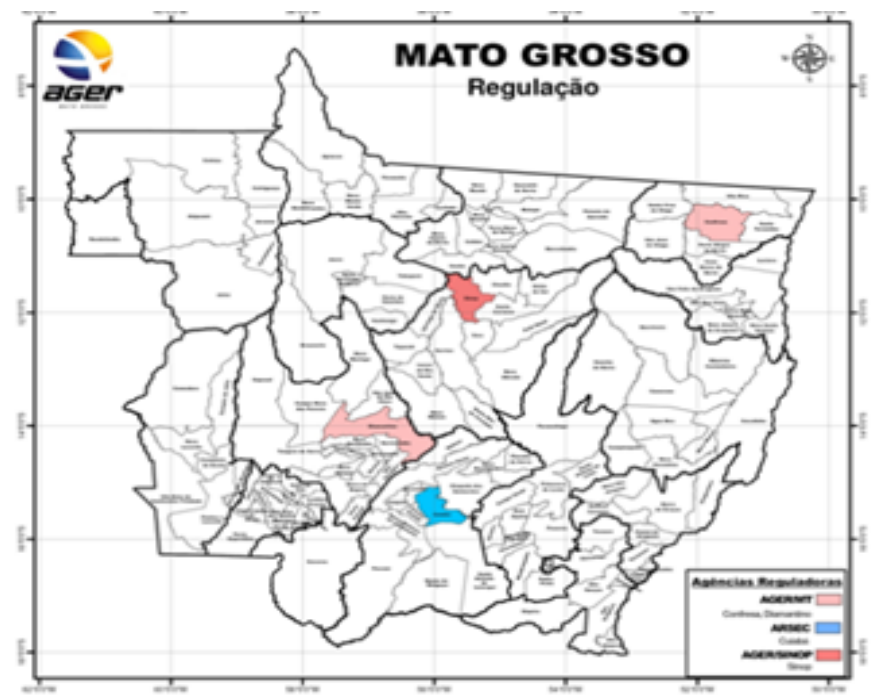

Figura 2. Panorama da atuação das Agências de Regulação nos municípios. Fonte: AGER, 2016.

Esse quadro revela a necessidade de se instituir o ente regulador, tanto para os prestadores públicos como privados e nos municípios visitados no projeto do PMSB verificou-se a necessidade de estruturação do poder concedente no que tange a regulação e fiscalização dos serviços e o devido fortalecimento do Controle Social como determina a lei 11.445/2007, sob pena de não se atingir as metas de universalização constantes no contrato da concessão e de se ficar refém das condições e restrições impostas pelo concessionário. 
A necessidade do ente regulador pode ser verificada quando se analisou a atuação do iniciativa privada. em várias situações, tais como: contratos de concessões, sem metas claras a serem atingidas ou em alguns casos muito precários na prestação dos serviços, atuação restrita a área urbana, ficando as áreas rurais totalmente desassistidas, tarifas mais elevadas, e ainda permanece índice de perdas elevados. Por outro lado, na prestação dos serviços públicos verificou-se a ausência de uma estrutura para realizar o gerenciamento dos serviços de água e com a distribuição de água sem o controle de qualidade e ainda municípios que nem mesmo efetuam a cobrança de uma tarifa mínima ou mesmo uma taxa de água. Situações mais precárias foram encontradas no consórcio 2, região próxima a baixada Cuiabana em municípios que mantiveram as suas instalações das Estações de Tratamento de Água, exatamente como receberam na época da municipalização e sem efetuarem manutenções mínimas e que resultaram em um grave problemas operacionais com consequente reflexo na qualidade da água distribuída.

\subsection{INDICADORES DO SISTEMA DE ABASTECIMENTO DE ÁGUA}

Os indicadores do sistema de abastecimento de água analisados dos prestadores públicos e privados permitiram avaliar o desempenho em relação a cobertura dos serviços de água, a intermitência presente no sistema, porcentagem de hidrometração e os índices de perdas registrados no sistema

Na Figura 3, é apresentado o tipo de captação de água utilizado nos 106 municípios para abastecimento da população do estado. Verifica-se que apesar da riqueza hídrica os mananciais superficiais, estes respondem $35 \%$ no setor público e $25 \%$ no privado, os subterrâneos constituem como fonte para $44 \%$ e $62 \%$ dos municípios e apresentam soluções mistas 19\% (público) e 12\% (privado).
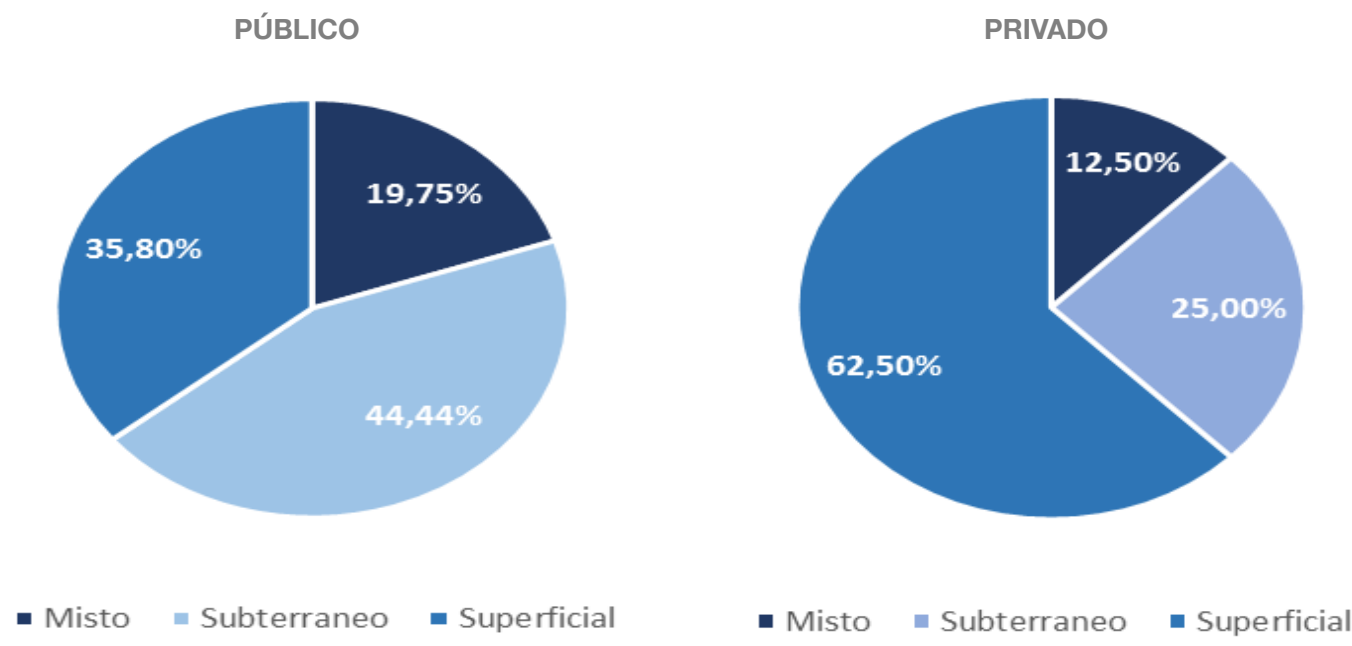

Figura 3. Tipo de captação nos municípios do Estado de Mato Grosso. Fonte: Autores.

Nos prestadores públicos e privados observam-se a predominância dos mananciais subterrâneos, em geral, por tratar-se de municípios com população abaixo de 10.000 hab.

Quanto aos nos prestadores privados o índice de cobertura no sistema de abastecimento de água alcança uma cobertura próxima à universalização do sistema nos municípios enquanto que nos prestadores públicos o percentual encontrado e menor porém dentro das medias de coberturas no País, que é de $88,3 \%$.

Verificou-se na Figura 4 (a) que 99\% das ligações são hidrometradas no setor privado e 91\% no setor público. Isto decorre das ações comerciais que são implementados nos sistemas privados 20 a $40 \% \mathrm{em}$ que percebe-se uma melhor estrutura das instalações.

Pode-se observar na Figura 4 (b) que no setor privado 17\% do sistema de abastecimento sofre intermitência e $83 \%$ não, e no setor público o índice é de $57 \%$ com intermitência e $43 \%$ sofrem. O regime de intermitência verificado nos municípios, muitas vezes decorre de uma forma de operação adotada pela equipe, pois via de regra o volume produzido é muito superior ao necessário e consumido pela população. Totsuka (2004) define três causas da adoção do regime de abastecimento intermitente, a primeira quando a disponibilidade hídrica da fonte de abastecimento é insuficiente para atender a demanda e fontes alternativas podem ser inviáveis ou 
estar localizadas distantes do local de consumo. A segunda quando a disponibilidade hídrica da fonte de abastecimento é suficiente para atender a demanda mas o planejamento é adequado, ou seja, gestão eficaz, porém não há recursos financeiros para implementar ações necessárias para minimizar ou eliminar o abastecimento intermitente. E a terceira devido a uma gestão não eficaz. Em geral, observou-se que nos municípios diagnosticados a escassez decorre da falta de planejamento e de recursos financeiros para implementar as ações e estão associadas aos desperdícios, vazamentos e perdas que acabam por comprometer a distribuição continua do abastecimento.
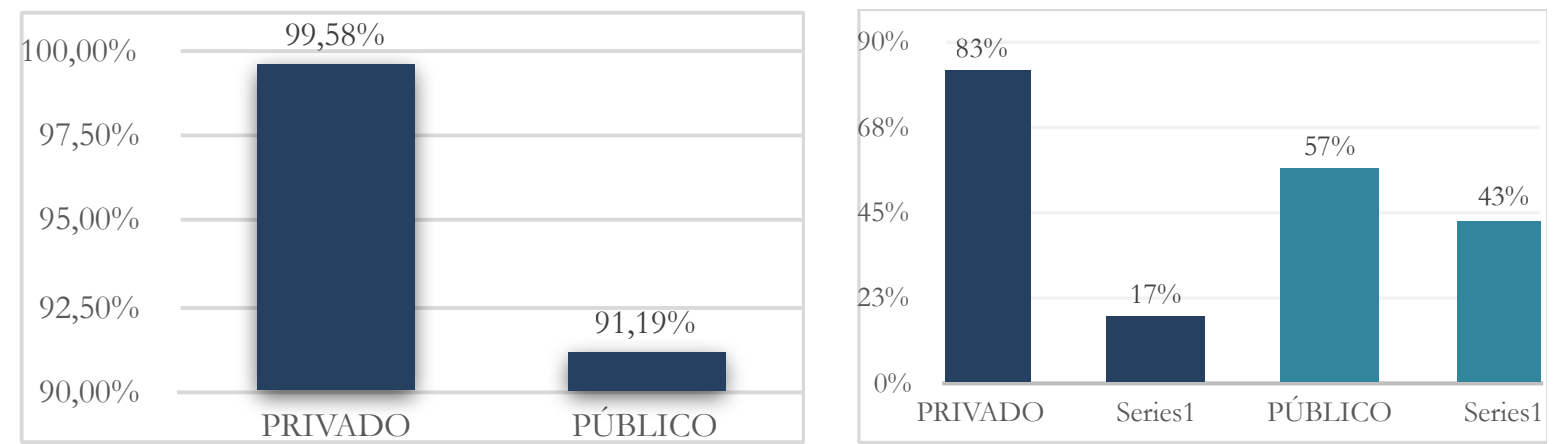

Figura 4. À esquerda, Índice de Hidrometração (4a), à direita, Índice de Intermitência (4b), municípios do Estado de Mato Grosso Fonte: Autores.

Verifica-se também que, o abastecimento em regime intermitente tem sido a solução adotada pelas prestadoras do serviço na tentativa de equacionar o problema do abastecimento de água, pois esta solução reduz os custos operacionais do sistema em curto prazo apesar de implicar em impactos negativos inclusive colocando em risco a saúde da população abastecida. Segundo Ormsbee \& Lansey (1994), essas situações de sistemas intermitentes têm se tornado uma tarefa complexa, pois apresentam como causas a falta de planejamento e necessário conhecer as causas que tem levado a esse regime de fornecimento, para que se busque uma reversão desse quadro. As soluções que se apresentam requerem adoções medidas de planejamento e investimentos em todas as unidades dos sistemas, permeado pelo desenvolvimento de vasto programa de educação ambiental.
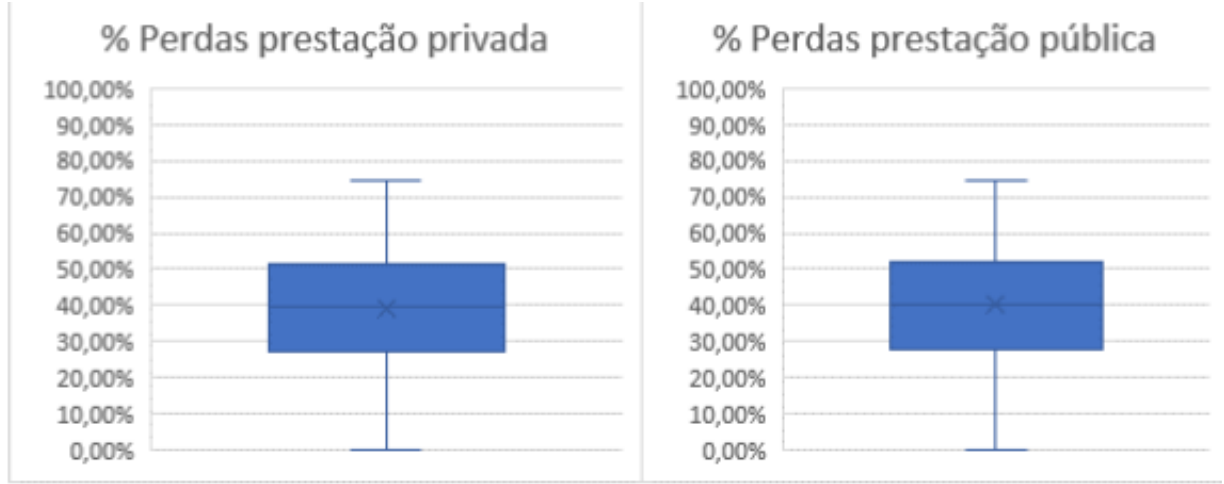

Figura 5. Índices de perdas (5a e 5b). Fonte: Autores.

Quanto ao índice de perdas no setor público apresentou uma média de 40\% e no setor privado 38\%. Índices estes considerados ruins e regulares respectivamente, mas dentro da média nacional de $37 \%$.

Quanto aos valores elevados no setor público verifica-se que a falta de investimento e gerenciamento, pode ser apontado com causas dessa situação e isso pode ser verificado, nos sistemas públicos que se encontram estruturados e com investimentos realizados na troca do parque de hidrômetros. Já, no setor privado verificase investimentos iniciais na substituição dos hidrômetros pois estes irão apresentar um retorno financeiro para a empresa, contudo, não se observa implementação de ações estruturais, como, substituição de redes e adutoras de cimento amianto que demandam investimentos maiores. Evidencia-se que a intermitência apresenta menores índices nos prestadores privados. 


\section{Consideraç̃es finais}

O modelo descentralizado adotado no estado de Mato Grosso demostra a necessidade de estabelecer um ordenamento institucional e da inserção do estado em formular e adequar a sua política de forma a atuar conjuntamente com os municípios.

Quanto à atividade de planejamento observa-se avanços com a finalização dos planos de saneamento e uma grande oportunidade de repactuação dos contratos com metas que atendam aos anseios da população e não somete o interesse dos concessionários e para tal fazendo inserção das áreas rurais. Do ponto de vista de prestação dos serviços verificou-se na atuação da iniciativa privada uma melhor capacidade gerencial e de arrecadação, porém sem a implementação de um ente regulador com a devida independência administrativa, técnica e financeira, o estado pode atingir a uma situação de monopólio privado, e ficar totalmente refém da vontade do concessionário, sem atender as metas definidas no s Planos de Saneamento. As concessões dos serviços, ao setor privado, não se mostram uma alternativa que atenda aos princípios da sustentabilidade, uma vez que o índice de perdas tem se demonstrado, ainda elevados e em patamares similares aos prestadores públicos. Quanto aos prestadores públicos, temos exemplos de sucesso, mas ainda persistem sistemas precários com baixo índice de hidrométrico e elevadas perdas.

Mostra-se a necessidade de estruturação do poder concedente no que tange a regulação e fiscalização dos serviços e o devido fortalecimento do Controle Social como determina a lei 11.445/2007, sob pena de não se atingir as metas de universalização e não prestação de um serviço que garanta a regularidade, continuidade e assegure uma qualidade da agua dentro dos padrões de potabilidade exigidos.

\section{Reierências}

Brasil (2007). Lei $n^{\circ} 11.445$, de 5 de janeiro de 2007. Lei do Saneamento. Estabelece diretrizes nacionais para o saneamento básico; altera as Leis $\mathrm{n}^{\circ}$ 6.766, de 19 de dezembro de 1979, 8.036, de 11 de maio de 1990, 8.666, de 21 de junho de 1993, 8.987, de 13 de fevereiro de 1995; revoga a Lei n 6.528, de 11 de maio de 1978; e dá outras providências. Recuperado de: <http://www.planalto.gov.br/ ccivil_03/_ato2007-2010/2007/lei/111445.htm>. Acesso em: 27 out. 2011.

Brasil (2010a). Decreto $n^{\circ}$ 7.217, de 21 de junbo de 2010. Regulamenta a Lei n ${ }^{\circ} 11.445$, de 5 de janeiro de 2007, que estabelece diretrizes nacionais para o saneamento básico, e dá outras providências. Recuperado de: <http:// www.planalto.gov.br/ccivil_03/_ato2007-2010/2010/Decreto/D7217.htm>. Acesso em: 27 out. 2011.

Pereira, T. S., \& Timóteo, H. L. (2015). Planos municipais de saneamento básico: avaliação de 18 casos brasileiros* Environmental sanitation municipal plans: an assessment of 18 Brazilian cases. Eng Sanit Ambient, 20(3) jul/set pp. 395-404.

Lambert, A. O., \& Hirner, W. H. (1999). Losses from Water Supply Systems: Standard Terminology and Recommended Performance Measures. IWA Blue Pages.

Lambert, A., \& Thornton, J. (2002). Avaliação de Perdas Reais [Relatório de Consultoria à Sabesp]. São Paulo : Sabesp.

Lima, E. B. N. R., \& Lima, G. A. R. (2014). Análise do Abastecimento de Água da Cidade de Cuiabá Relatório Técnico, Requerente: Ministério Público do Estado de Mato Grosso/Núcleo de Defesa da Cidadania e do Consumidor de Cuiabá/6a Promotoria Cível Dr. Ezequiel Borges de Campos — Promotor de Justiça Ofício n.0 434/2013/6ª PJ].

Philippi Jr., A., \& Galvão Jr., A. de C. (1988). Gestão do Saneamento Básico: Abastecimento de Água e Esgotamento Sanitário. Barueri [SP]: Manole, 2012. Coleção Ambiental (vários autores).

Martins, G. (2001). Impacto do Saneamento Básico na Saúde Pública. Tese de doutorado, Faculdade de Saúde Pública,Universidade de São Paulo, São Paulo, SP, Brasil.

Totsuka, N., Trifunovic, N., \& Vairavamoorthy, K. (2004). Intermittent Urban Water Supply Under Water Starving Situations. Proceedings 30th WEDC International Conference, Vientiane, 2004. 